\title{
Injection Molding of Rubber Compound Influenced by Injection Mold Surface Roughness
}

\author{
Michal Stanek ${ }^{1, a}$, David Manas ${ }^{1, b}$, Miroslav Manas ${ }^{1, c}$, Martin Ovsik ${ }^{1, d}$, Vojtech \\ Senkerik $^{1, \mathrm{e}}$, Adam Skrobak ${ }^{1, \mathrm{f}}$ \\ ${ }^{1}$ Tomas Bata University in Zlin, TGM 5555, 76001 Zlin, Czech Republic \\ astanek@ft.utb.cz, ${ }^{\mathrm{b}} \mathrm{dmanas@ft.utb.cz,}{ }^{\mathrm{c}} \mathrm{manas@ft.utb.cz,}{ }^{\mathrm{d}} \mathrm{ovsik@ft.utb.cz,}{ }^{\mathrm{e}} \mathrm{v}$ senkerik@ft.utb.cz, \\ 'skrobak@ft.utb.cz
}

Keywords: Injection molding, mold, surface, roughness, fluidity, rubber.

\begin{abstract}
.
Delivery of polymer melts into the mold cavity is the most important stage of the injection molding process. This paper shows the influence of cavity surface roughness and technological parameters on the flow length of rubber into mold cavity. The fluidity of polymers is affected by many parameters (mold design, melt temperature, injection rate and pressures) and by the flow properties of polymers. Results of the experiments carried out with selected types of rubber compounds proved a minimal influence of surface roughness of the runners on the polymer melt flow. This considers excluding (if the conditions allow it) the very complex and expensive finishing operations from the technological process as the influence of the surface roughness on the flow characteristics does not seem to play as important role as was previously thought. Application of the measurement results may have significant influence on the production of shaping parts of the injection molds especially in changing the so far used processes and substituting them by less costly production processes which might increase the competitiveness of the tool producers and shorten the time between product plan and its implementation.
\end{abstract}

\section{Introduction}

Injection molding is one of the most extended polymer processing technologies. It enables the manufacture of final products, which do not require any further operations. The tools used for their production - the injection molds - are very complicated assemblies that are made using several technologies and materials. Working of shaping cavities is the major problem involving not only the cavity of the mold itself, giving the shape and dimensions of the future product, but also the flow pathway (runners) leading the polymer melt to the separate cavities. The runner may be very complex and in most cases takes up to $50 \%$ volume of the product itself (cavity). In practice, high quality of runner surface is still very often required. Hence surface polishing for perfect conditions for melt flow is demanded. The stated finishing operations are very time and money consuming leading to high costs of the tool production. The fluidity of polymers is affected by many parameters (mold design, melt temperature, injection rate and pressures) and by the flow properties of polymers. Results of the experiments carried out with different rubber c proved a minimal influence of surface roughness of the runners on the polymer melt flow. This considers excluding (if the conditions allow it) the very complex and expensive finishing operations from the technological process as the influence of the surface roughness on the flow characteristics does not seem to play as important role as was previously thought. A plastic nucleus is formed by this way of laminar flow, which enables the compression of the melt in the mold and consecutive creeping.

A constant flowing rate given by the axial movement of the screw is chosen for most of the flows. During filling the mold cavity the plastic material does not slide along the mold surface but it is rolled over. This type of laminar flow is usually described as a "fountain flow". 


\section{Injection molding}

The injection mold (Fig. 6) was designed for the easiest possible manipulation with the mold itself and during injection molding while changing the testing plates. A spiral shape cavity was designed and produced for injection molding rubber compounds.
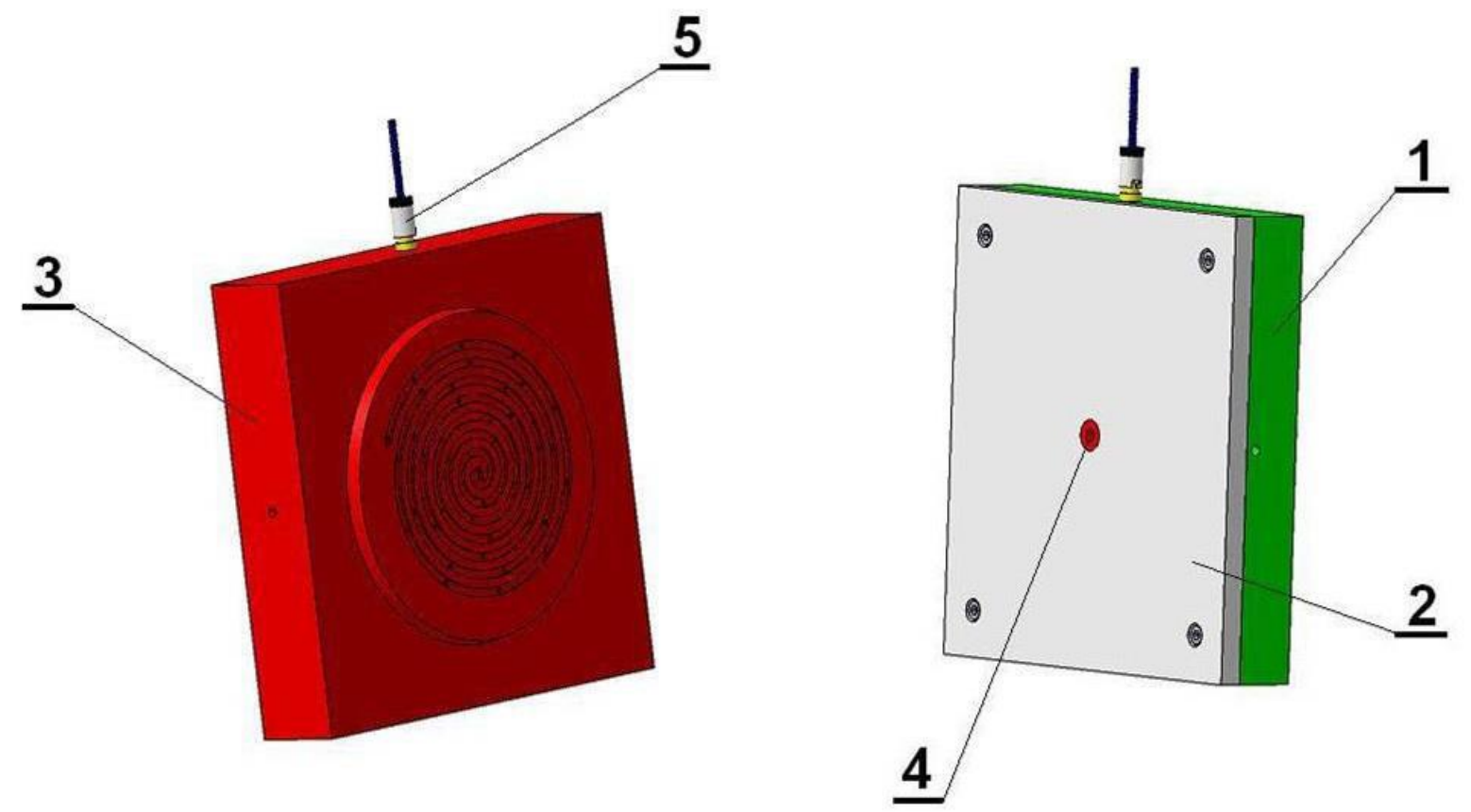

Fig. 1 Testing injection mold

a) upper side, b) bottom side

1- clamping plate, 2 - testing plate, 3 - cavity plate, 4 - sprue insert, 5 - temperature sensor

The injection mold can operate with 5 exchangeable testing plates with different surface roughness. The surface of the plates was machined by four different technologies, which are most commonly used to work down the cavities of molds and runners, represented by roughness arithmetic deviation Ra. These technologies are polishing, grinding, milling and electro-spark erosion. The testing plates are used for changing the surface of the mold cavity.

Table 1 Surfaces of testing plates

\begin{tabular}{|c|c|c|c|c|c|}
\hline $\begin{array}{c}\text { Plate } \\
\text { surface }\end{array}$ & Polished plate & Grinded plate & $\begin{array}{c}\text { Electro - spark } \\
\text { machined plate } \\
\text { with a fine } \\
\text { design }\end{array}$ & Milled plate & $\begin{array}{c}\text { Electro - spark } \\
\text { machined plate with } \\
\text { a rough design }\end{array}$ \\
\hline $\mathrm{Ra}[\mu \mathrm{m}]$ & 0,029 & 0,369 & 3,520 & 9,368 & 17,393 \\
\hline $\begin{array}{l}\text { Surface } \\
\text { photo }\end{array}$ & & & & & \\
\hline
\end{tabular}

The surface of the plates was machined by four different technologies, which are most commonly used to work down the cavities of molds and runners in industrial production. These technologies are polishing, grinding, milling and two types of electro-spark erosion - fine and rough design (Table 1). The testing plates are made from tool steel (DIN 1.2325) whose are used for simple and fast changing the surface of the mold cavity.

Injection molding machine REP V27/Y125 with electrical heating system of the mold has been used for testing samples production. The process parameters should be changed during the samples injection molding, especially the injection pressure and surface of the testing plates. 
Representatives of rubber compounds with varying properties were chosen for the experiment with the other decisive criteria being representation of almost all kinds of materials that are commonly used in injection molding process for the technical parts production (Tab. 2).

The prepared rubber compounds were supplied in the form of long strips for easier feeding to the injection molding machine.

Table 2 Testing compounds

\begin{tabular}{|c|c|c|c|c|c|c|}
\hline Compound & Type & $\begin{array}{c}\text { hardness } \\
{[\mathrm{ShA}]}\end{array}$ & $\begin{array}{c}\text { density } \\
{\left[\mathrm{g} . \mathrm{cm}^{-3}\right]}\end{array}$ & $\begin{array}{c}\text { strength } \\
{[\mathrm{MPa}]}\end{array}$ & $\begin{array}{c}\text { tensibility } \\
{[\%]}\end{array}$ & $\begin{array}{c}\text { Mooney } \\
\text { viscosity }\left(1+4 \mathrm{~min} / 100^{\circ} \mathrm{C}\right) \\
{\left[{ }^{\circ} \mathrm{MU}\right]}\end{array}$ \\
\hline A & NBR & $50 \pm 5$ & $1,21 \pm 0,02$ & 10 & 300 & 31 \\
\hline B & CR/NR/SBR & $60 \pm 5$ & $1,32 \pm 0,02$ & 10 & 250 & 40 \\
\hline
\end{tabular}

\section{Results}

The aim of the measurements was to find out the influence of separate technological parameters, especially the quality of the injection mold cavity surface, on the flow length of the injected materials.

The influence of injection molding pressure and surface roughness of the testing plates on filling the mold cavity were observed when injection molding separate rubber compounds. The curing time was set up on the same level for all compounds in spate of different mixtures composition.

\section{Influence of material fluidity on surface roughness}

Influence of the flow length on surface quality is shown on the next pictures. The surface quality was changed by the testing plates with different surface roughness (Table 1).
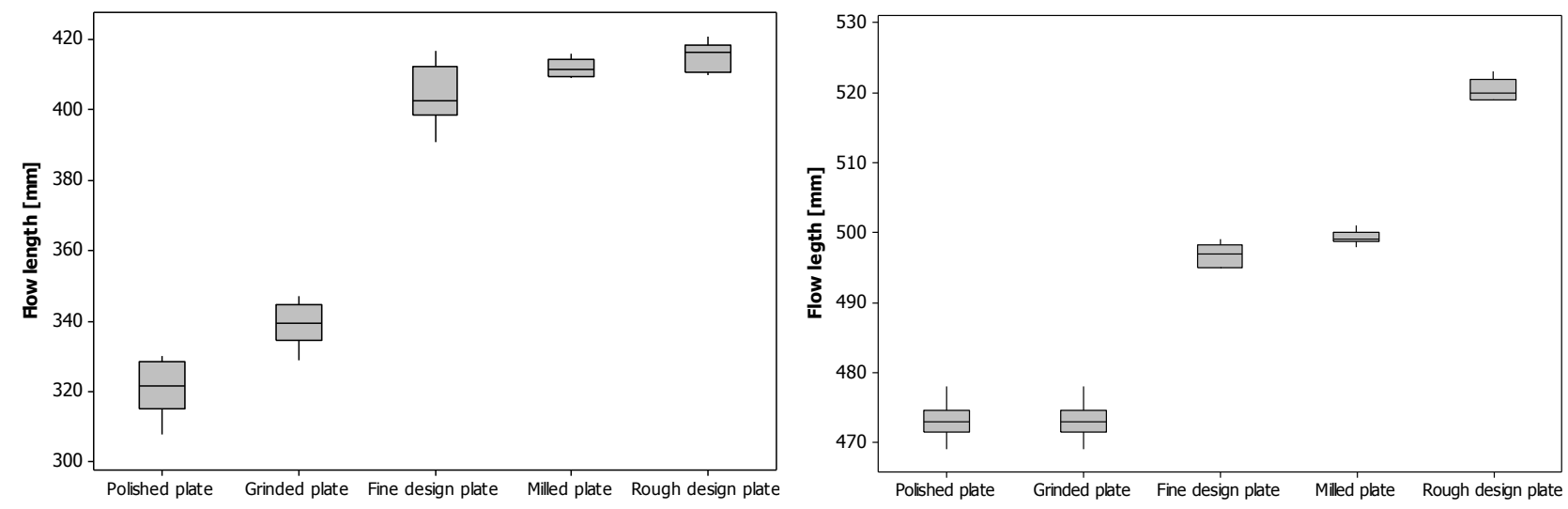

Fig. 2 Influence of surface quality on the flow length

(Compound A left, Compound B right)

\section{Influence of injection pressure on material fluidity}

Logically with the higher injection pressure the length of testing spirals were longer. This was observed on all testing plates. 

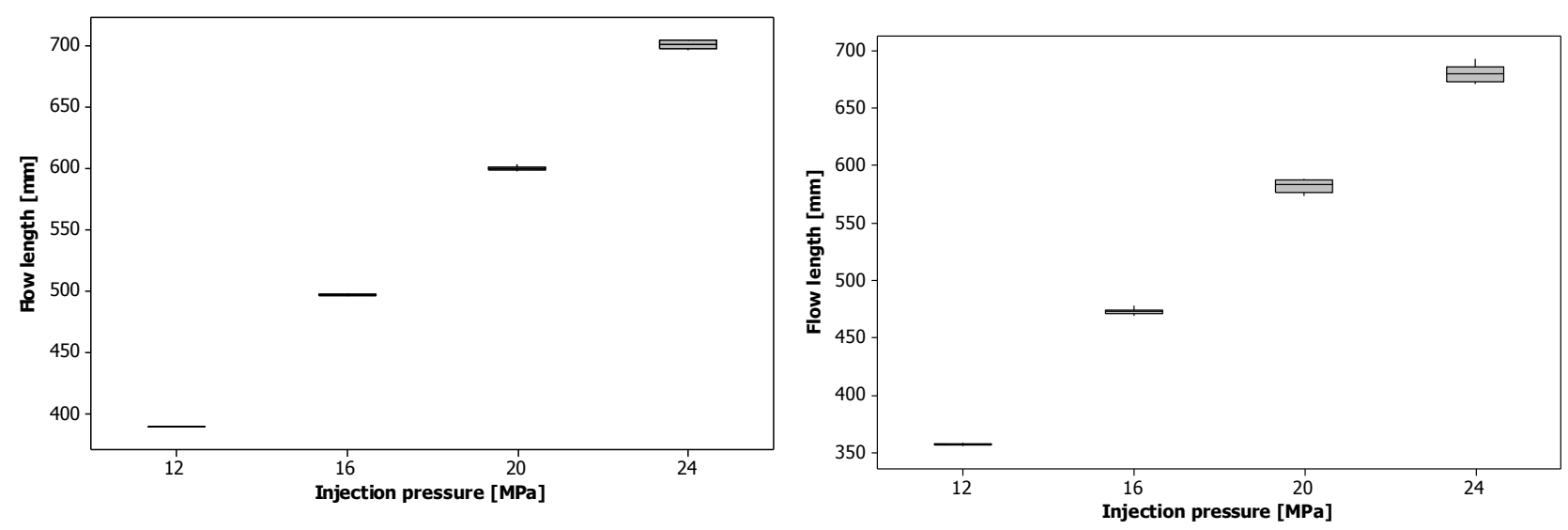

Fig. 3 Influence of the injection pressure on flow length

(Polished plate left, Grinded plate right)
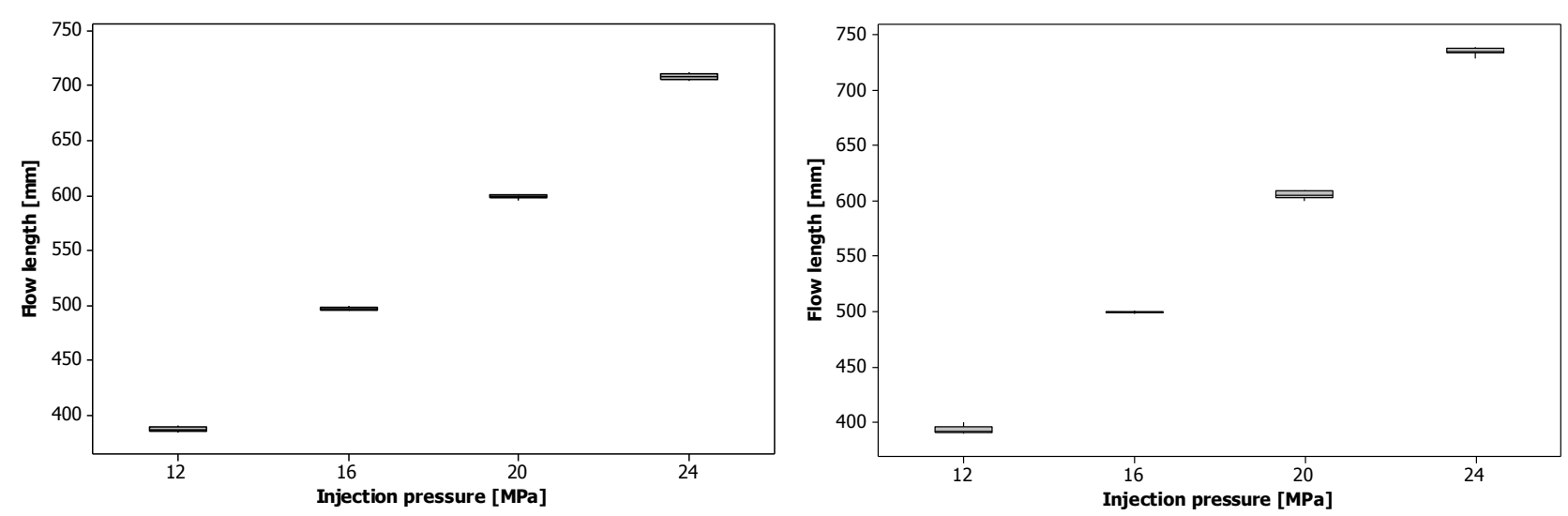

Fig. 4 Influence of the injection pressure on flow length

(Fine design plate left, Milled plate right)

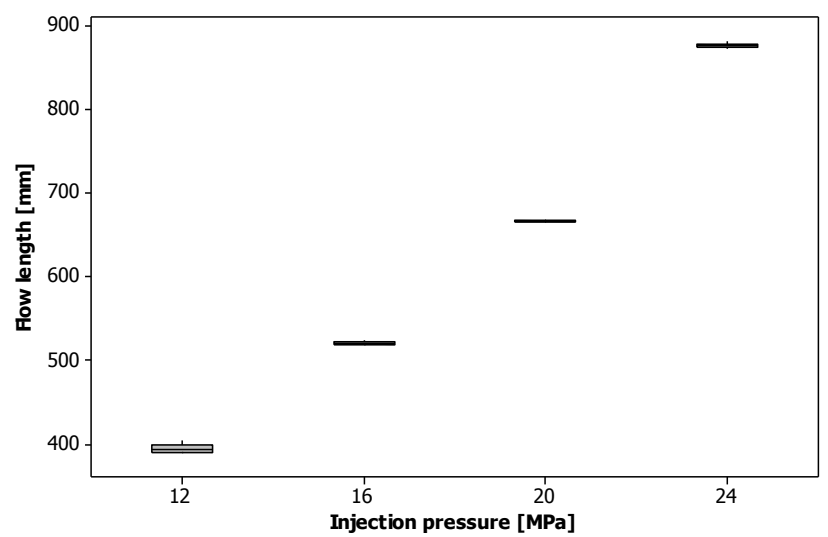

Fig. 5 Influence of the injection pressure on flow length (Rough design plate)

For better imagination results can be seen in 3D graph (example - compound B on Fig. 6) where is shown the influence of injection pressure and surface roughness on flow length is. 


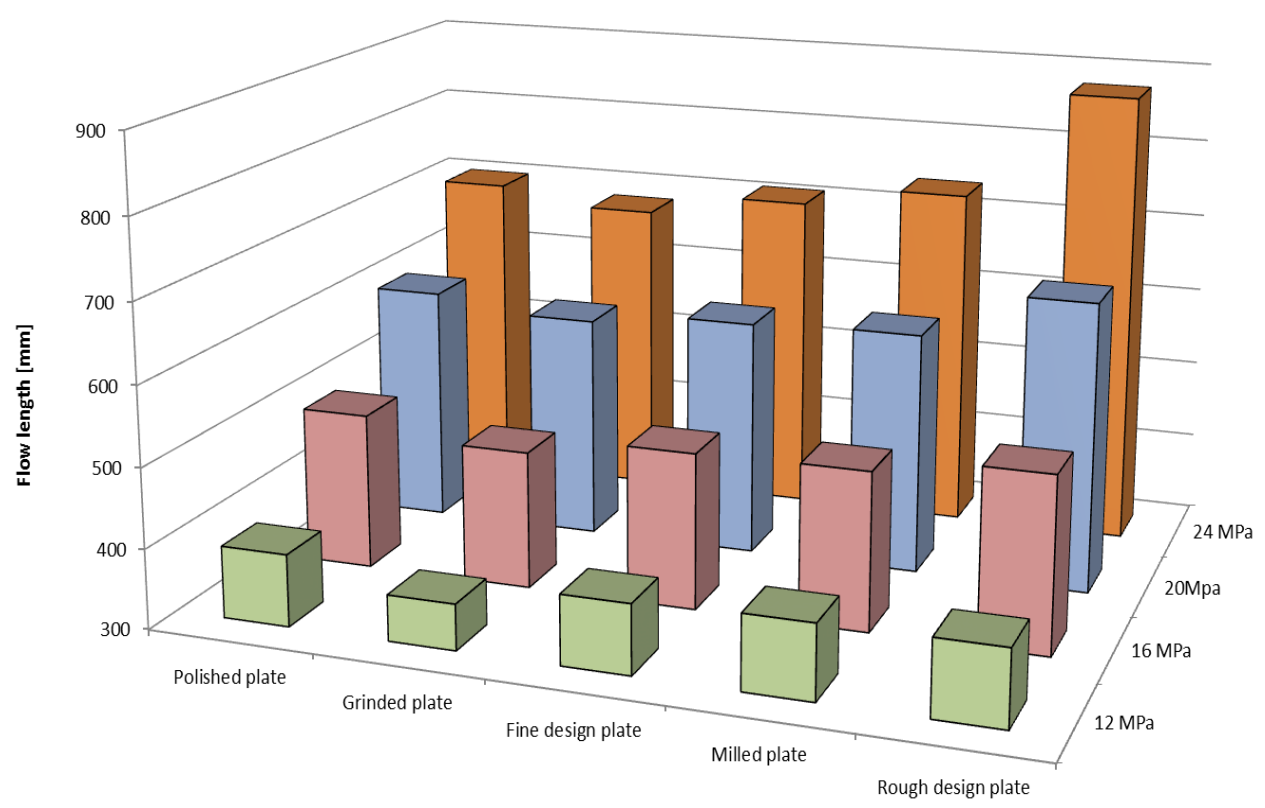

Fig. 6 Influence of the flow length on surface quality

\section{Summary}

This research looked into the influence of technological parameters on filling of the injection mold cavity and the flow length respectively.

Measurement shows that surface quality does not have substantial influence on the length of flow. Samples which were injected into the spiral (cavity) with the worst surface quality have approximately same length of flow. This can be directly put into practice. It also suggests that final working and machining (e.g. grinding and polishing) of some parts of the injection mold, especially the runners and gates, are not necessary. These findings are very important from the point of view of use in production. For verification of these results further experiments have to be carried out using different rubber compounds.

\section{Acknowledgment}

This paper is supported by the internal grant of TBU in Zlin No. IGA/FT/2014/016 funded from the resources of specific university research and by the European Regional Development Fund under the project CEBIA-Tech No. CZ.1.05/2.1.00/03.0089 and Technology Agency of the Czech Republic as a part of the project called TA03010724 AV and EV LED luminaire with a higher degree of protection.

\section{References}

[1] D. Manas, M. Manas, M.Stanek, S. Sanda, V. Pata, "Thermal Effects on Steels at Different Methods of Separation“, 2011, Chemicke listy, Volume 105, Issue 17, pp. S713-S715

[2] D. Manas, M. Stanek, M. Manas, V. Pata, J. Javorik, "Influence of Mechanical Properties on Wear of Heavily Stressed Rubber Parts", KGK - KautschukGummiKunststoffe, 62. Jahrgang, 2009, p.240-245.

[3] Stanek, M., Manas, M., Manas, D., "Mold Cavity Roughness vs. Flow of Polymer", Novel Trends in Rheology III, AIP, 2009, pp.75-85. 